pulmonary venous flow of these patients with a systemicopulmonary shunt or banding. ${ }^{10}$ Asplenia was identified as predictive of mortality, but because only a limited number of our patients died of sepsis, one could wonder whether asplenia is not a surrogate for having a right atrial isomerism and thereby more complex cardiac lesions. We have recently demonstrated that patients with dextrocardia with single ventricle palliation had poor long-term outcomes, although this parameter had not been previously identified as a predictor of mortality. ${ }^{14}$ In our study, we identified that $85 \%$ of patients with dextrocardia and atrial isomerism had atrioventricular regurgitation at the time of presentation. It is possible that the technical difficulty of achieving a sustainable repair in these patients contributed to their mortality. It seems to be corroborated by Anagnostopoulos and colleagues, ${ }^{4}$ who identified atrioventricular valve regurgitation to be a predictive factor for mortality in atrial isomerism.

It was striking to notice that our attempts to achieve biventricular repair in patients with right atrial isomerism failed to the extent that only 1 out of 12 patients survived and that this parameter was independently predictive of mortality in patients with right atrial isomerism. It still seems to us premature to decide that no patients with right atrial isomerism should be directed toward a biventricular repair, but it appears clear that extreme caution should be exerted in these decisions in cases where both approaches could be offered.

\section{Strengths and Weaknesses}

Compared with the previously published literature on the subject, our series is very large and for the first time gives perspectives of survival up to adulthood. The study spans a long time period and slight variation of practice may not have been captured. In this heterogeneous group of patients some parameters contributing to poor outcomes may not have been present in sufficient numbers to be revealed as influencing outcomes.

\section{CONCLUSIONS}

In our experience, there has been no improvement in outcomes after cardiac surgery in patients with atrial isomerism: One-quarter of those with left atrial isomerism and one-half of those with right atrial isomerism still die before reaching adulthood. Despite advances in modern surgical techniques, the outcome of such patients remains poor. Only a fraction of those with obstructed pulmonary veins survive. Undergoing a biventricular repair does not confer a survival advantage to those born with right atrial isomerism.

You can watch a Webcast of this AATS meeting presentation by going to: http://webcast.aats.org/2014/files/ Tuesday/20140429_220PM_240pmPM_Yves_d'Udekem_ Jayapadaman_Bhaskar.mp4.

\section{References}

1. Hashmi A, Abu-Sulaiman R, McCrindle BW, Smallhorn JF, Williams WG, Freedom RM. Management and outcomes of right atrial isomerism: a 26-year experience. J Am Coll Cardiol. 1998;31:1120-6.

2. Gilljam T, McCrindle BW, Smallhorn JF, Williams WG, Freedom RM. Outcomes of left atrial isomerism over a 28-year period at a single institution. J Am Coll Cardiol. 2000;36:908-16.

3. Ota N, Fujimoto Y, Murata M, Tosaka Y, Ide Y, Tachi M, et al. Improving outcomes of the surgical management of right atrial isomerism. Ann Thorac Surg. 2012;93:832-8; discussion 838-9.

4. Anagnostopoulos PV, Pearl JM, Octave C, Cohen M, Gruessner A, Wintering E, et al. Improved current era outcomes in patients with heterotaxy syndromes. Eur J Cardiothorac Surg. 2009;35:871-7; discussion 877-8.

5. Morales DLS, Braud BE, Booth JH, Graves DE, Heinle JS, McKenzie ED, et al. Heterotaxy patients with total anomalous pulmonary venous return: improving surgical results. Ann Thorac Surg. 2006;82:1621-7; discussion 1627-8.

6. Yun T-J, Al-Radi OO, Adatia I, Caldarone CA, Coles JG, Williams WG, et al. Contemporary management of right atrial isomerism: effect of evolving therapeutic strategies. J Thorac Cardiovasc Surg. 2006;131:1108-13.

7. Lim JSL, McCrindle BW, Smallhorn JF, Golding F, Caldarone CA, Taketazu M, et al. Clinical features, management, and outcome of children with fetal and postnatal diagnoses of isomerism syndromes. Circulation. 2005;112:2454-61.

8. Eronen MP, Aittomäki KA, Kajantie EO, Sairanen HI. Outcome of left atrial isomerism at a single institution. Pediatr Cardiol. 2012;33:596-600.

9. Sinzobahamvya N, Arenz C, Reckers J, Photiadis J, Murin P, Schindler E, et al. Poor outcome for patients with totally anomalous pulmonary venous connection and functionally single ventricle. Cardiol Young. 2009;19:594-600.

10. Nakayama Y, Hiramatsu T, Iwata Y, Okamura T, Konuma T, Matsumura G, et al Surgical results for functional univentricular heart with total anomalous pulmonary venous connection over a 25-year experience. Ann Thorac Surg. 2012;93:606-13.

11. Eronen MP, Aittomäki KA, Kajantie EO, Sairanen HI, Pesonen EJ. The outcome of patients with right atrial isomerism is poor. Pediatr Cardiol. 2013;34:302-7.

12. Cheung YF, Cheng VY, Chau AK, Chiu CS, Yung TC, Leung MP. Outcome of infants with right atrial isomerism: is prognosis better with normal pulmonary venous drainage? Heart. 2002;87:146-52.

13. Ohuchi H, Kagisaki K, Miyazaki A, Kitano M, Yazaki S, Sakaguchi H, et al Impact of the evolution of the Fontan operation on early and late mortality: a single-center experience of 405 patients over 3 decades. Ann Thorac Surg. 2011;92:1457-66.

14. Poh CL, Xu M, Galati JC, Iyengar AJ, Cheung M, Brizard CP, et al. Surgical palliation in patients with a single ventricle and dextrocardia. $J$ Thorac Cardiovasc Surg. 2014;148:1475-80.

\section{Discussion}

Dr Glen Van Arsdell (Toronto, Ontario, Canada). Dr Bhaskar and colleagues have tackled a very difficult problem-isomerism. Seventy-four percent of patients who had left atrial isomerism survived to 18 years, and about $50 \%$ of those who had right atrial isomerism survived. It is very nuanced, this disease, and I want to ask 2 questions related to that nuance, mostly right atrial isomerism.

About half of your left atrial isomerism patients wound up with a biventricular heart, about $80 \%$ of your right atrial isomerisms wound up with a univentricular heart, and then of a few who had an attempt of a biventricular repair, ultimately all didn't make it.

This isn't the first time we've seen reports of complex biventricular repairs actually having a worse outcome than single ventricle repairs. I can think of a classic article by Stark from Great Ormond Street about 20 years ago. There is also an article from our group about 10 years ago with similar findings with the double outlet right ventricle.

But it seems to me this is a different disease and a lot of the issue probably is around the total anomalous pulmonary venous return. And the question is the timing of the biventricular repair. Because certainly there are some biventricular repairs that are successful in 
right atrial isomerism. So is this a situation where we should be thinking about staging our treatment of right atrial isomerism if we want to get to a biventricular heart? In other words, doing a veins repair when it is necessary and then coming back at a later date. Are we doing too much at once? Do you have any insight into that?

Dr Bhaskar. That is a good question. As you say, the right atrial isomerism with total anomalous pulmonary venous connection (TAPVC) is a different cohort of patients. Going by the intention-to-treat principle we channeled these patients into a biventricular repair pathway. But of the 12 cases in this cohort, only 2 had a biventricular repair. The others died even before we got to that stage. Although they had 2 good ventricles with adequate size and function, having obstructed TAPVC made managing the disease in these patients more difficult. I'm not quite sure where we can go from here, because we haven't reached the biventricular stage in those patients and they died during the neonatal period. The median survival was just 45 days.

Dr Van Arsdell. Understood. So you were actually already staging these patients and still failed to have success.

Dr Bhaskar. In a way, yes.

Dr Van Arsdell. The second question relates to the problem of neonates with severe obstruction. When I first joined the Hospital for Sick Children, families were given the option of taking their child home to die. Oddly enough they didn't all die. So some parents would say: "Let's go ahead and proceed with surgery." And we would operate on them at age 2, 3, and 4 months and those patients seemed to do well.

Not surprisingly that colored our thinking and we reinstituted therapy with the general principle being if we can stent a vertical vein, if we can make a stented connection between the confluence and the left atrium, if we can accept mild to moderate obstruction and not operate on them, perhaps we can get some of these through. Have you had any opportunity to chase after that, some type of modified strategy to see whether you can improve the outcome for these patients?

Dr Bhaskar. That's a good question, because what we have noticed is that some of these patients may not have clinically evident obstruction of their pulmonary veins. However they become apparent after receiving a systemic to pulmonary shunt, thus snowballing the clinical course of events. From my own experience I cannot comment on any modified strategy. Dr Brizard might want to give his thoughts on this.

Dr Christian Brizard (Parkville, Victoria, Australia). I'm not as familiar as Dr Bhaskar with the data, but we have not recently instituted any alternative strategy for obstructed TAPVC.

Dr Charles Fraser (Houston, Tex). I may have missed it in your presentation, but did you talk about late abdominal complications in this group of patients?
Dr Bhaskar. We did not. Although not highlighted in this presentation, about one-third of the patients had malrotation of the gut, $50 \%$ of whom underwent Ladd procedure.

Dr Fraser. I bring that point up just because we are in the era of segmentalized care. We often forget that these children have significant issues below the diaphragm. What is your policy in Melbourne with regard to prophylactic follow-up of the visceral rotational abnormalities that are often prevalent, and probably even more specific about the liberal use of some sort of protective procedure like a Ladd procedure?

Dr Bhaskar. We don't have a policy for prophylactic Ladd procedure as far as I know; however, these patients are currently seen by the surgical team on a regular basis, providing a holistic approach to management. The database does go way back to the 1970s; however, currently there is no practice of prophylactic Ladd procedure.

Dr Robert Jaquiss (Durham, NC). To follow-up on Dr Fraser's question and in keeping with Dr Backer's liberal use of informal polls of the audience: We struggle with this in our institution. The cardiac surgeons believe a prophylactic Ladd procedure should be done and the pediatric surgeons don't.

When I asked for a show of hands in the audience for how many would arrange for a pediatric surgeon to perform some sort of Ladd procedure when the patient is an asymptomatic child with an isomerism who is known to have malrotation, and how many would observe and wait for a catastrophe, it came out about even. This is the state of the science. It looks like there is a role for a study here.

Dr Christopher Caldarone (Toronto, Ontario, Canada). We all agree that operating on obstructed pulmonary veins is a good idea, but a lot of these patients present with shades of obstruction. It could be that we are waiting for obstruction that's way too obvious and maybe should be decompressing the pulmonary veins much more liberally. What's your threshold for determining whether pulmonary veins are obstructed?

Dr Bhaskar. I think we are guided by the echo findings. We don't have a practice of prophylactic decompression of the pulmonary veins.

Dr Caldarone. So what type of gradient drives you? And of course, you have to take that within the context of what the pulmonary inflow is, which makes it even harder.

Dr Bhaskar. Yes, that makes it even harder, because most of these patients have atresia or pulmonary stenosis and you wouldn't know until you put in a shunt.

Dr Caldarone. And therein lies the trouble.

Dr Brizard. Minimal gradient would trigger surgery on the veins. At the time when the patient is duct-dependent, any acceleration would trigger a surgery on the vein at the time of the palliation. So minimal gradient, yes. 